\title{
STUDI COOLING CAPACITY KAPAL CEPAT RUDAL 60 METER (STUDI KASUS PADA KCR 60 BATCH DI PT PAL INDONESIA)
}

\author{
Bobby Xaverius ${ }^{1}$, Helmy Taufan ${ }^{2}$, Novi Sukma Drastiawati ${ }^{3}$ \\ ${ }^{1,3}$ Teknik Mesin/S-1 Teknik Mesin Manufaktur, Universitas Negeri Surabaya \\ bobbyxaverius@mhs.unesa.ac.id \\ novidrastiawati@unesa.ac.id \\ ${ }^{2} \mathrm{PT}$. PAL INDONESIA \\ helmytaufan@pal.ac.id
}

\begin{abstract}
Abstrak- Perkembangan dunia perkapalan maupun dunia maritim harus diimbangi dengan peningkatan mutu alat transportasi, terutama untuk alat transportasi laut. Pada alat transportasi tersebut beban pendinginan pada tiap ruangan perlu dilakukan perhitungan secara teliti untuk mendapatkan nilai efisiensi yang baik. Tujuan dari studi ini adalah untuk menganalisis dan mengetahui parameter-parameter yang mempengaruhi nilai dari kapasitas pendinginan pada Kapal Cepat Rudal 60 Meter, seperti parameter volume ruang, parameter kondisi udara luar dan udara dalam ruang, parameter beban panas yang diderita pada ruangan, parameter Fresh Air, parameter psychrometric diagram, serta kapasitas pendinginan yang dibutuhkan. Metode yang digunakan adalah menghitung nilai h yang didapatkan dari psychrometric chart. Langkah selanjutnya adalah menentukan nilai RSHF. Langkah ketiga adalah menentukan cooling capacity tiap ruangan. Hasil yang didapatkan adalah nilai dari total kapasitas pendingin (Cooling Capacity) yang dibutuhkan oleh kompresor pada ruang akomodasi Kapal Cepat Rudal 60 Meter sebesar 174,17 kW. Hasil tersebut dari perincian data berupa kapal dirancang dalam Summer Condition (iklim tropis) dengan temperatur inside $=22^{\circ} \mathrm{C}$ dan temperature outside $=35^{\circ} \mathrm{C}$, Jumlah Beban Panas Transmisi = 20651Watt, Jumlah Beban Panas Jendela = 1192 Watt, Jumlah Beban Panas Lampu $=56817$ Watt, Jumlah Beban Panas Penghuni (Sensible + Latent) $=104494$ Watt, Jumlah Beban Panas Peralatan $=12400$ Watt, Jumlah Beban Panas Total $=103737$ Watt.
\end{abstract}

Kata Kunci- Cooling Capacity, Kapal Cepat Rudal 60 meter, beban panas, ruang akomodasi kapal, kondisi udara.

\begin{abstract}
The development of the shipping and maritime world must be balanced with an increase in the quality of transportation equipment, especially for sea transportation. On these transportation equipment, the cooling load in each room needs to be done carefully to get a good efficiency value. The purpose of this study is to analyse and determine the parameters that affect the value of the cooling capacity of the 60-meter Missile Fast Ship, such as the room volume parameters, the parameters of the outside air and indoor air conditions, the heat load parameters suffered in the room, the Fresh Air parameters, psychrometric diagram parameters, and cooling capacity required. The method used is to calculate the $h$ value obtained from the psychrometric chart. The next step is to determine the RSHF value. The third step is to determine the cooling capacity of each room. The results obtained are the value of the total cooling capacity (Cooling Capacity) required by the compressor in the accommodation room 60 meters Missile Fast Ship of $174.17 \mathrm{~kW}$. The results of the data breakdown in the form of a ship designed in Summer Condition (tropical climate) with inside temperature $=22^{\circ} \mathrm{C}$ and outside temperature $=35^{\circ} \mathrm{C}$, Total Heat Transmission Load = 20651 Watt, Total Heat Load Window = 1192 Watt, Total Heat Load of Lamp = 56817 Watt, Total Occupant Heat Load $($ Sensible + Latent $)=104494$ Watt, Total Equipment Heat Load = 12400 Watt, Total Heat Load = 103737 Watt.
\end{abstract}

Keywords - Cooling Capacity; Fast Ship Missile 60 meters; heat load; ship accommodation spaces; air condition

\section{PENDAHULUAN}

Negara Kesatuan Republik Indonesia sudah dikenal sejak dulu sebagai negara maritim, yaitu negara yang mempunyai wilayah perairan luas. Total luas wilayah Indonesia adalah 2.001.648,97 $\mathrm{km}^{2}$, dengan luas wilayah lautan sebesar $4,85 \%$ dari total wilayah Indonesia. Sehingga luas lautan Indonesia adalah $96.079,15 \mathrm{~km}^{2}$
(Meutia Faradilla, 2017: 1). Supaya masyarakat Indonesia bisa memanfaatkan sumber daya laut yang melimpah, maka dibutuhkan transportasi untuk menunjang produktifitas mereka. Seiring berkembangnya teknologi maka diperlukan transportasi laut yang mumpuni, yaitu kapal.

Perkembangan dunia perkapalan maupun dunia maritim harus diimbangi dengan peningkatan mutu alat 
transportasi. Indonesia patut berbangga dengan perusahaan galangan kapal yang mampu bersaing ditingkat internasional, yaitu PT. PAL Indonesia (Persero). Perusahaan galangan kapal ini didukung peralatan yang lengkap dan canggih serta memenuhi standar internasional, sehingga PT. PAL Indonesia (Persero) mendapat kepercayaan dari perusahaan pelayaran dan pengangkutan barang di seluruh dunia. Hal ini dapat dilihat dari banyaknya pesanan kapal dari negara lain, seperti: Jerman, Turki, Malaysia, dan Filipina.

Pada kapal laut perhitungan kapasitas pendingin dibutuhkan sebagai pendukung ketika kapal dioperasikan. Kapasitas pendinginan ini merupakan suatu hal yang penting dalam kenyamanan personal pada kapal, menjaga kondisi udara sekitar, dan melindungi peralatan-peralatan elektronik pada kapal, untuk mencari kapasitas pendinginan dalam suatu kapal dibagi dalam banyak tahap dan dipengaruhi oleh beberapa parameter panas yang ditimbulkan, seperti panas pada dinding, panas yang ditimbulkan oleh penghuni, panas dari lampu, dan panas dari peralatan.

Penelitian tentang perhitungan beban pendinginan (cooling capacity) pada ruangan di perkantoran PT. Indonesia Power UP JP PESANGGARAN BALI dilakukan dengan menggunakan perhitungan beban pendinginan maksimal digunakan sebagai dasar untuk menentukan kapasitas absorption chiller. Perhitungan beban pendinginan dibagi menjadi 4 bagian, yaitu: beban pendinginan karena adanya perbedaan antara temperatur udara dalam ruangan dalam temperatur udara luar ruangan. Hal ini meliputi seluruh selubung bangunan yaitu dinding, sistem jendela, dan atap. Perhitungan kedua mencakup beban pendinginan yang berasal dari masuknya radiasi matahari ke dalam ruangan baik melalui sistem jendela maupun melalui penerangan alami dari sisi atap. Perhitungan ketiga dengan beban pendinginan yang berasal dari beban internal, meliputi manusia di dalam gedung / ruangan, peralatan pencahayaan, dan berbagai peralatan yang menghasilkan panas seperti printer, komputer,dan televise. Langkah keempat dengan menghitung beban pendinginan yang berasal dari infiltrasi udara yaitu beban dari udara yang masuk melalui celah pintu, buka-tutup pintu, atau dari jendela. Perhitungan beban pendingin berdasarkan pada SNI 6389-2011 dan ASHRAE. Hasil yang didapatkan pada penelitian tersebut adalah total beban pendinginan siang hari di PT. Indonesia Power UPJP Bali pada pukul 07:00-17:00 adalah sebesar 565,97 $\mathrm{kW}$ dan total beban pendinginan pada malam hari pada pukul 17:00-07:00 adalah sebesar 346,56 kW. Dengan demikian beban pendinginan total di PT. Indonesia Power UPJP Bali adalah $912,54 \mathrm{~kW}[2]$.

Peningkatan kinerja pada sistem pendingin diteliti dengan menggunakan metode yang menggunakan bahan eksperimen sistem pendingin udara baru dengan gabungan kondensor dan pendinginan evaporative independent. Sistem ini terdiri dari pendingin evaporatif dan sistem pendingin kompresi uap, alat ukur, dan perangkat kontrol. Pada tahap pengukuran menggunakan laju aliran air dari pendingin evaporatif jenis sheel dan tube diukur menggunakan pengukur aliran volume dengan akurasi \pm
$0,5 \%$, total laju aliran udara kipas evaporatif dikontrol oleh konverter frekuensi. Anemometer digunakan untuk mengukur laju aliran udara (maksimum 4,8 m/s). Kelembaban relatif diukur menggunakan psikrometer dengan akurasi $1 \%$. Termogun digunakan untuk mengukur berbagai suhu, dan data yang dikumpulkan dianalisa. Komponen sistem pendingin yang terdiri dari satu kompresor, pompa air pendingin evaporatif, dan kipas daya satu fase diukur dengan secara terpisah. Kapasitas pendinginan dapat dihitung dengan menerapkan persamaan keseimbangan energi. Hail yang didapatkan peningkatan kinerja pada sistem pendingin udara dengan gabungan kondensor-pendingin evaporatif, dan variasi antara faktorfaktor yang dipengaruhi, seperti suhu masuk air evaporator, suhu bola-bola kering, kecepatan udara dan tingkat semprotan air, kapasitas pendinginan, COP telah dianalisis. Kesimpulan utama didapatkan sebagai berikut. Uji eksperimental menunjukkan bahwa kapasitas pendinginan dan COP dari sistem pendingin udara dengan gabungan kondensor-pendingin evaporativ meningkat secara signifikan dengan meningkatnya suhu masuk air evaporator, kecepatan udara dan laju semprotan air. COP meningkat $12 \%$ dengan kecepatan udara meningkat dari 4,0 menjadi 4,8 $\mathrm{m} / \mathrm{s}$ dan dengan laju semprotan meningkat dari 0,03 sampai $0,0 \mathrm{~kg} / \mathrm{m}$-s. Juga ditemukan bahwa peningkatan suhu udara bola kering akan menurunkan COP [3].

Analisis pada performa cooling tower dilakukan dengan menggunakan pengukuran performa Menara pendingin LCT 400 dimana pengukuran performa melalui range, approach, efektifitas, dan membuat grafik hasil pengukuran performa cooling tower beradasarkan waktu dari temperatur rata-rata udara yang keluar dengan temperatur rata-rata udara yang masuk. Hail tersebut dibandingkan dengan berupa erbandingan $\mathrm{L} / \mathrm{G}$ cooling tower adalah perbandingan untuk laju alir massa air dan udara. Setiap cooling tower memiliki desain tertentu, perubahan karena musim memerlukan perubahan laju aliran air dan udara untuk mendapatkan efektifitas yang terbaik dari cooling tower. Perubahan dapat dilakukan dengan merubah beban kontak atau perubahan sudut siripnya. Aturan pada termodinamika mengatakan bahwa panas yang dibuang harus sama dengan panas yang diserap oleh udara lingkungan [4].

Pada Penerapan Evaporative Cooling Untuk Peningkatan Kinerja Mesin Pengkondisian Udara Tipe Terpisah (AC Split) menggunakan metode studi literatur pada penggunaan EC pada mesin refrigerasi siklus kompresi uap yang ditempatkan pada kondensor. Tahap berikutnya dikembangkan sebuah modul EC yang ditempatkan pada kondensor. Penelitian ini dilakukan secara eksperimental menggunakan AC Split 1 PK dengan Refrigeran HCR-22 (refrigeran hidrokarbon) dengan penambahan sistem evaporative cooling pada kondensor, untuk mengetahui seberapa besar pengaruh perubahan debit air yang diterima media evaporative pad terhadap perubahan temperatur input ke kondensor, tekanan kompresor dan evaporator, dan koefisien kinerja (COP) mesin pendingin tipe terpisah (AC Split). Media evaporative pad yang digunakan terbuat dari bahan kertas 
khusus yang dapat menyerap air namun tidak merubah fisik kertas. Kertas yang digunakan adalah jenis orrugated paper. Peralatan atau unit mesin pendingin yang digunakan dalam pengujian ini adalah mesin pengkondisian udara dengan penambahan sistem evaporative cooling pada kondensor (outdoor unit) data yang dianalisis adalah temperatur input dan output pada kondensor, tekanan kompresor dan evaporator. Koefisien kinerja (Coeficient of Performance, COP) mesin pendingin tipe terpisah. Hasil yang didapatkan menunjukkan bahwa penerapan Evaporative Cooling akan memberikan kinerja mesin pengkondisian udara tipe terpisah (AS Split) yang lebih baik pada laju aliran air ke EC yang lebih tinggi $(1,22$ $\mathrm{L} /$ menit). Semakin besar debit air yang dialirkan ke media evaporative pad pada sistem Evaporative Cooling (EC), maka semakin rendah temperatur input dan output ke kondensor. Semakin rendah pula tekanan yang diperoleh kompresor dan evaporator sehingga koefisien kinerja COP lebih baik $(20 \%)$ atau lebih hemat energi, bila dibanding pada kondisi tanpa Evaporative Cooling (TEC) atau AC Split standar [5].

Perhitungan kapasitas pendingin pada kapal tanker menggunakan metode dengan dasar perhitungan HVAC di dalam ruangan untuk heat calculation, kapasitas udara, perhitungan sirkulasi udara, perhitungan entalphy, dan psychrometric diagram. Hasil yang didapatkan adalah total kapasitas pendingin (Cooling Capacity) yang dibutuhkan oleh kompresor pada ruang akomodasi Kapal Tanker 17500 LTDW ditemukan sebesar 487,87 KW. Adapun dengan rincian data sebagai berikut: Kapal dirancang dalam Summer Condition (iklim tropis) sesuai permintaan customer dengan inside condition : temperature $=24^{\circ} \mathrm{C}$ dan relative humidity $=50 \%$. Pada outside condition temperature $=35^{\circ} \mathrm{C}$ dan relative humidity $=70 \%$. Jumlah Beban Panas Transmisi $=36127.82$ Watt. Jumlah Beban Panas Jendela $=3449.88$ Watt. Jumlah Beban Panas Lampu $=148037.79$ Watt. Jumlah Beban Panas Penghuni $=12182$ Watt. Jumlah Beban Panas Peralatan $=11000$ Watt. Jumlah Beban Panas Total $=210797.48$ Watt. Jumlah Air Capacity yang dibutuhkan $=21252.42 \mathrm{~m}^{3} / \mathrm{h}[6]$.

Pada penelitian ini bagian yang menjadi analisis adalah HVAC yang merupakan singkatan dari Heating, Ventilation, and Air Conditioning, yang mana sistem pengkondisian udara inimerupakan aplikasi dari beberapa cabang ilmu Mechanical Engineering yaitu termodinamika, mekanika fluida, dan perpindahan panas. Disebut "sistem" karena terdiri dari beberapa mesin yang masing-masing memiliki fungsi yang berbeda, yang terintegrasi sedemikian rupa sehingga membentuk suatu sistem tata udara yang dapat mengontrol suhu, kelembaban, tekanan udara, tingkat kebersihan, pola aliran udara serta jumlah pergantian udara di ruang produksi sesuai dengan persyaratan ruangan yang telah ditentukan. Dalam dunia perkapalan HVAC digunakan untuk mendesain sistem pendinginan dan sirkulasi udara dalam setiap ruangan di dalam kapal, sehigga dapat memberikan kenyamanan bagi awak kapal, untuk melindungi kwalitas muatan, untuk ventilasi dan pembebasan gas pada ruang pompa kapal tanker dan sebagainya. HVAC juga berfungsi untuk menjaga suhu ruangan dan sirkulasi udara yang didalamnya terdapat peralatan control atau engine seperti control room, engine room, dan workshop[7].

\section{METODE}

Metode yang digunakan dalam menentukan beban pendinginan (cooling capacity) pada kapal cepat rudal 60meter (KCR 60 Batch) adalah dengan perhitungan melalui General Arranggement (GA) yang dibuat oleh PT PAL Indonesia. Berdasarkan data tersebut dilakukan perhitungan volume ruangan, jumlah penghuni ruangan, suhu dan kelembaban, peralatan listrik (equipment), jumlah lampu, jumlah jendela,jenis ruangan yang membutuhkan pendinginan berdasarkan kegunaan, dan posisi ruangan. Selanjutnya dapat dihitung entalpi, kapasitas udara, jumlah sirkulasi, \% fresh air, dan cooling capacity pada suatu ruangan.

Dasar yang dilakukan untuk perhitungan adalah perhitungan HVAC didalam ruangan yang meliputi [8] :

\section{Heat Calculation}

Sumber beban panas yang diderita ruangan berasal dari :

a) Beban panas akibat transmisi (rambatan) melewati dinding, plafond dan juga lantai ruangan $(\mathrm{Q}$ transmisson $=\mathrm{QTr})$

b) Beban panas dari panas penghuni ruangan $(\mathrm{Q}$ Person $=\mathrm{QP}$ )

c) Beban panas dari panas rambatan dari jendela $(\mathrm{Q}$ Window $=\mathrm{QW}$ )

d) Beban panas dari penggunaan lampu peneranga (Q Lamp $=$ QL)

e) Beban panas dari peralatan yang digunakan dalam ruangan ( $Q$ Machine=QM). Sehingga total beban panas yang ditanggung oleh mesin pendingin (QT) :

Qtotal $=$ QTr + Qp + Qw + QL + Qm

2. Kapasitas Udara dihhitung berdasarkan formula sebagia berikut :

$\mathrm{V}=\mathrm{Qr} /(\rho . \mathrm{Cp} . \Delta \mathrm{t})(2.6)$

$\mathrm{v}=$ Kapasitas udara $\left(\mathrm{m}^{3} / \mathrm{h}\right)$

$\mathrm{Qr}=$ Total panas yang diderita ruang ( watt )

$\boldsymbol{\rho}=$ densitas udara $\left(1.2 \mathrm{~kg} / \mathrm{m}^{3}\right)$

$\mathrm{Cp}=$ Panas Spesifik udara $\left(1 \mathrm{KJ} / \mathrm{KG}^{\circ} \mathrm{C}\right)$

$\Delta \mathrm{t}=$ Perbedaan temperatur udara yang masuk ruang dengan temperatur ruang $\left({ }^{\circ} \mathrm{C}\right)$ untuk kenyamanan manusia, maka sebaiknya $\Delta \mathrm{t}$ tidak lebih dari $10^{\circ} \mathrm{C}$.

3. Perhitungan Sirkulasi Udara (Air Changes) diderita ruang dengan formula sebagai berikut :

$\mathrm{Lw}=\mathrm{v} / \mathrm{V}(2.7)$

Lw $=$ Air Change $(\mathrm{x} / \mathrm{h})$

$\mathrm{v}=$ Kapasitas udara yang masuk $/$ keluar $\left(\mathrm{m}^{3} / \mathrm{h}\right)$

$\mathrm{V}=$ Volume ruang $\left(\mathrm{m}^{3}\right)$

4. Perhitungan Enthalphy

5. Perhitungan dengan Psychrometric Diagram Psikrometrik adalah bidang yang mempelajari tentang

bagaimana menentukan sifat-sifat fisis dan termodinamika suatu gas yang didalamnya terdapat campuran antara gas-uap. Sebagai contoh adalah menentukan sifat-sifat dari campuran udara dan uap air. 
Adapun sifat-sifat tersebut anatara lain: Dry Bulb Temperature, Wet Bulb Temperature, Dew Point, Relative Humidity, Humidity Ratio, Enthalpy, Volume

Spesific.Psikometrik diagram merupakan penggambaran secara grafis untuk beberapa properti penting dari udara lembab [9].

6. Kapasitas Pendingin (Cooling Capacity)

Kapasitas beban pendinginan

diperoleh sesuai formula di bawah ini.

$\mathrm{QC}=\mathrm{v} . \rho . \Delta \mathrm{h}$

$\mathrm{QC}=$ kapasitas beban pendingin.

$\mathrm{v}=$ Kapasitas udara yang akan disuplai ke dalam

ruang. $\left(\mathrm{m}^{3} / \mathrm{h}\right)$

$\rho=$ Densitas udara.

$\Delta \mathrm{h}=$ Perbedaan enthalphy antara dua udara yang masuk unit temperatur terendah dalam unit cooler. (Temperatur terendah tercapai saat $\mathrm{RH} \pm 95 \%$ ).

Perhitungan parameter yang menentukan cooling capacity antara lain:

a) Menghitung jumlah orang dalam setiap ruangan berdasarkan kegunaan dan jumlah kursi yang tersedia.

b) Menentukan $\mathrm{RH}$ (Relative Humidity) Temperature Inside dan Outside, biasanya telah ditetapkan oleh maker (pembuat kapal).

c) Menghitung parameter Wall (F-A Wall, Side Wall, Floor).

d) Menentukan dan menghitung ruangan mana yang mempunyai jendela, jenis jendela (sun shine atau shadow), berapa jumlah jendela, dan berapa luas dari jendela tersebut.

e) Menentukan besar panas dari lampu yang digunakan dalam ruangan (Incandescent atau Fluorescent). Umumnya lampu yangdigunakan untuk ruang akomodasi kapaladalah tipe Fluorescent.

f) Menentukan panas dari peralatan dalam ruangan, panas ini tergantung dari jenis dan kapasitas peralatan yang terpasang dalam ruangan tersebut.

g) Menghitung panas yang berasal dari penghuni, menurut ASHRAE 1964 Guide and Data Book Heat Gain from People (for Marine AirConditioning Loads).

h) Menghitung Heat Calculation yang diperoleh dengan menjumlahkan parameter wall, window, light, equipment, dan person.

i) Menentukan sirkulasi udara (Air Change) di setiap ruangan.

j) Menghitung kapasitas udara dalam ruangan dengan menggunakan rumus: volume ruang $\mathrm{x}$ Air Change.

k) Menghitung nilai dari FA yang diperoleh dari konstanta $30 \mathrm{x}$ jumlah orang.

1) Menghitung nilai \%FA yang diperoleh dari FA / (Air Capacity x 100). m) Perhitungan parameter Psychrometric Diagram dan Cooling Capacity pada kapal cepat rudal 60 meter.

\section{HASIL DAN DISKUSI}

Untuk Perhitungan pada psikrometri diagram dapat dicari dengan cara: Letakkan titik 1 pada titik potong garis $35^{\circ} \mathrm{C}$ (DBT) dan $\mathrm{RH} 70 \%$, letakkan titik 2 pada titik potong garis $22^{\circ} \mathrm{C}$ (DBT) dan $\mathrm{RH} 50 \%$, tarik garis lurus dari titik 1 menuju titik 2, letakkan titik A dengan menggambar garis vertikal dan horizontal melalui titik 1 dan 2 berturut-turut, cari titik 3 dengan cara menghitung panjang garis yang dibentuk oleh titik 1 dan 2 dikali dengan $\% \mathrm{FA}$, titik ini disebut dengan titik Mixing.

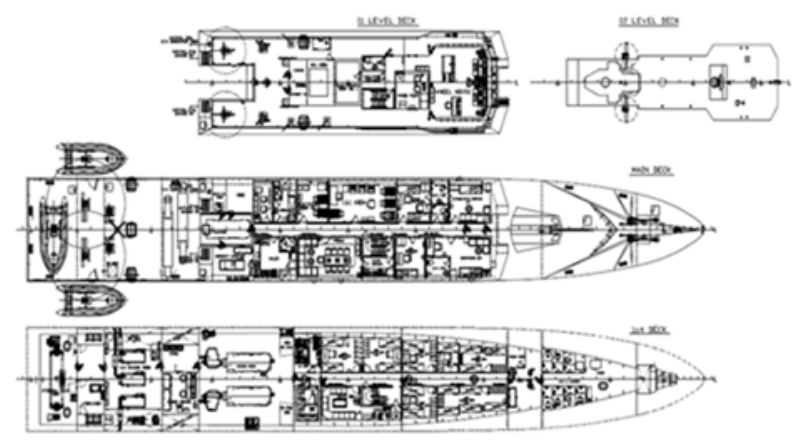

Gambar 1. General Arrangement Cepat Rudal 60 Meter.

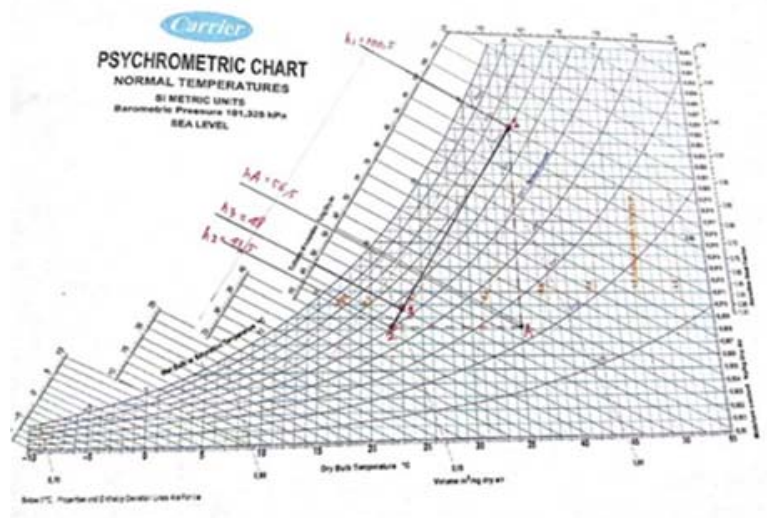

Gambar 2. Psychrometric Chart.

Dari psychrometric chart, didapat data sebagai berikut: $\mathrm{h} 1=100 \mathrm{kj} / \mathrm{kg}$ of dry air, h2 =43,5 kj/kg of dry air, hA = $57 \mathrm{kj} / \mathrm{kg}$ of dry air, h3 = $48 \mathrm{kj} / \mathrm{kg}$ of dry air. Cari nilai RSHF, $\quad \mathrm{RSHF}=\mathrm{RSH} /(\mathrm{RSH}+\mathrm{RLH}) \quad(16,931$ $\mathrm{kW}) /(16,931+0,388 \mathrm{~kW})=0,97$, tandai hasil perhitungan RSHF $=0,97$ pada SHF skala point, dari titik 2, gambar lurus dari garis 2 menuju pada skala SHF, garis ini yang disebut garis RSHF. Titik 4 didapat pada titik potong garis RSHF dan RH 95\%, tarik garis dari titik 3 menuju garis saturasi melalui titik 4. Titik ini merupakan titik $\mathrm{T}$ coil. Perhitungan Kapasitas Pendinginan (Cooling Capacity) h1 $=100 \mathrm{kj} / \mathrm{kg}$ of dry air, h2 $=43,5 \mathrm{kj} / \mathrm{kg}$ of dry air, $\mathrm{hA}=57$ $\mathrm{kj} / \mathrm{kg}$ of dry air, h3 = $48 \mathrm{kj} / \mathrm{kg}$ of dry air, h4 $=30,5 \mathrm{kj} / \mathrm{kg}$ of dry air. Mass of air entering the room, M_a $=$ (Total room heat $) /($ Total heat sermoved) $(\mathrm{RSH}+\overline{\mathrm{R}} \mathrm{LH}) /(\mathrm{h} 2-\mathrm{h} 4)=$ $(16,913+0,388 \mathrm{~kW}) /(48-30,5 \mathrm{kj} / \mathrm{kg})=0,98 \mathrm{~kg} / \mathrm{s}$. Capacity 
of the plant (Wheel House room) $=$ M_a (h_3- h_4) $=0,98$ $\mathrm{kg} / \mathrm{s} \mathrm{x}(17,5 \mathrm{kj} / \mathrm{kg})=17,15$ kilowatt.

Tabel I. Hasil Perhitungan Cooling Capacity Tiap Ruangan

\begin{tabular}{|c|c|c|c|}
\hline \multirow{3}{*}{ No. } & \multirow{3}{*}{ Deck } & \multirow{3}{*}{ Room } & $\begin{array}{l}\text { Cooling } \\
\text { Capacity }\end{array}$ \\
\hline & & & QC \\
\hline & & & $(\mathbf{k W})$ \\
\hline 1 & 01 Level Deck & Electronics Room No. 1 & 8.72 \\
\hline 2 & 01 Level Deck & Electronics Workshop & 7.14 \\
\hline 3 & 01 Level Deck & Radio Room & 5.89 \\
\hline 4 & 01 Level Deck & Wheel House & 17.15 \\
\hline 5 & Main Deck & Executife Officer & 3.12 \\
\hline 6 & Main Deck & Chief Enginer & 1.95 \\
\hline 7 & Main Deck & C.I.C Room & 13.02 \\
\hline 8 & Main Deck & Electronics Room No. 2 & 6.74 \\
\hline 9 & Main Deck & Medical & 2.19 \\
\hline 10 & Main Deck & Commandemen Room & 3.21 \\
\hline 11 & Main Deck & Galley & 6.00 \\
\hline 12 & Main Deck & No Name & 18.14 \\
\hline 13 & Main Deck & Pantry Officer & 1.54 \\
\hline 14 & Main Deck & No 1 Officer & 3.75 \\
\hline 15 & Main Deck & Commanding Off & 3.84 \\
\hline 16 & 1st Deck & No 2 Officers & 6.58 \\
\hline 17 & 1st Deck & No 1 Patty Off & 6.42 \\
\hline 18 & 1st Deck & No 2 Patty Off & 6.17 \\
\hline 19 & 1st Deck & No 3 Patty Off & 6.40 \\
\hline 20 & 1st Deck & No 4 Patty Off & 3.18 \\
\hline 21 & 1st Deck & Lounge Room & 11.22 \\
\hline 22 & 1st Deck & Laundry & 2.36 \\
\hline 23 & 1st Deck & No 1 Rating Off & 5.30 \\
\hline 24 & 1st Deck & No 2 Rating Off & 3.85 \\
\hline 25 & 1st Deck & Rifles store & 4.27 \\
\hline 26 & 1st Deck & Hoist Room & 2.07 \\
\hline 27 & 1st Deck & Store & 6.47 \\
\hline 28 & 1st Deck & LAV \& Laundry & 5.94 \\
\hline 29 & Base Line & Amunition Room & 1.54 \\
\hline & & & 174, \\
\hline
\end{tabular}

\section{KESIMPULAN}

Berdasarkan dari tujuan khusus dan pembahasan diatas, maka dapat diambil kesimpulan sebagai berikut: total kapasitas pendingin (Cooling Capacity) yang dibutuhkan oleh kompresor pada ruang akomodasi Kapal Cepat Rudal 60 meter ditemukan sebesar 174,17 kW. Adapun dengan rincian data sebagai berikut: kapal dirancang dalam summer condition (iklim tropis) dengan temperature inside $=22^{\circ} \mathrm{C}$ dan temperature outside $=35^{\circ} \mathrm{C}$, jumlah beban panas transmisi $=20651$ watt, jumlah beban panas jendela $=1192$ watt, jumlah beban panas lampu $=56817$ watt, jumlah beban panas penghuni (Sensible + Latent $)=104494$ watt, jumlah beban panas peralatan $=12400$ watt, jumlah beban panas total $=103737$ Watt.

\section{REFERENS}

[1] Faradilla Meutia. Proses Pengecatan Pada Bottom Zone Lambung Kapal LPD (Landing Platform Deck). Laporan Praktik Industri Jursan Teknik Mesin, 2017.

[2] Suntoro Dedi, S. Darmawan Ragil, Ahadi Khalif. Perhitungan Beban Pendinginan Pada Ruangan Di Perkantoran PT. INDONESIA POWER UPJP Pesanggaran Bali. Ketenagalistrikan dan Energi Terbarukan Vol. 17 No. 1. 2018. pp. 19-30.
[3] Rachman Arfidian, Sulaiman, Syafrul Hadi. Peningkatan Kinerja Sistem Pendingin Kompresi Uap Menggunakan Gabungan Kondensor-Pendingin Evaporatif. Jurnal Teknik Mesin Institu Teknologi Padang Vol 8 No 1. 2018. pp 22-26.

[4] Handoyo Yopi. Analisis Performa Cooling Tower LCT 400 Pada P.T. XYZ, Tambun Bekasi. Jurnal Ilmiah Teknik Mesin Volume 3 Nomor 1. 2015. pp. 38-52.

[5] Aziz Azridjal, Idral, Herisiswanto, Mainil Iman Rahmat. Penerapan Evaporative Cooling Untuk Peningkatan Kinerja Mesin Pengkondisian Udara Tipe Terpisah (AC Split). Proceeding Seminar Nasional Tahunan Teknik Mesin XIV (SNTTM XIV). 2015.

[6] Syah SS, Drastiawati NS, Taufan H. Perhitungan Cooling Capacity Yang Dibutuhkan Pada Kapal Tanker 17500 LTDW. OTOPRO. 2019 Jun 18;14(1):6-12.

[7] Utomo, B. Sistem Ventilasi dalam Kapal. Teknik. 2007. 28(1), 7682.

[8] Swenson, S. Don. HVAC - Heating, Ventilating, and Air Conditioning. Third Edition. Amer Technical Pub.2003.

[9] Moran, M. J., \& Shapiro, H. N. Fundamentals of engineering. thermodynamics: SI version. Chichester: John Wiley. 1998. 